\title{
Simultaneous measurement of blood-flow velocity and regional wall motion with phase unwrapping
}

\author{
Junmin Liu' ${ }^{1 *}$, James A White ${ }^{1,2}$, Maria Drangova ${ }^{1,3}$ \\ From 15th Annual SCMR Scientific Sessions \\ Orlando, FL, USA. 2-5 February 2012
}

\section{Summary}

In this study we offer a unique approach to achieve simultaneous evaluation of tissue and blood flow velocities from a single "low-VENC" image dataset (i.e.: prescribed for measurement of tissue velocities). A novel phase unwrapping algorithm is tested for this purpose.

\section{Background}

Doppler echocardiography-based techniques are routinely used to assess the heart and ventricular function by measuring blood flow and cardiac tissue velocity profiles. While these measures may similarly be obtained by phase contrast MRI, each require separate acquisitions and subsequent analysis to accommodate for vastly different velocities and therefore velocity encoding (VENC) values.

\section{Methods}

MR imaging was performed on a 3.0-T whole-body scanner (MR 750, GE Medical Systems). Phase-contrast images with through-plane velocity-encoding were acquired in the short-axis plane with a retrospectively triggered $2 \mathrm{D}$ fast cine phase contrast pulse sequence (TR/TE, 7.3/4.4 ms; flip angle, 15 degree, slice thickness $8 \mathrm{~mm}$ ) with first-order flow compensation in all dimensions to minimize artifacts from flow and motion. Three VENCs - 75, 20 and $10 \mathrm{~cm} / \mathrm{s}$ - were used and the images acquired with VENC $=75 \mathrm{~cm} / \mathrm{s}$ were used as a reference. The acquisition time (per VENC) was about 15 seconds, enabling acquisition within a single breathhold. Thirty images were reconstructed per cardiac

\footnotetext{
'Imaging Research Laboratories, Robarts Research Institute, Schulich School of Medicine \& Dentistry, The University of Western Ontario, London, ON, Canada

Full list of author information is available at the end of the article
}

cycle. Phase unwrapping of the velocity data was achieved using an algorithm developed in our lab, which uses an orthogonal recursive approach to remove streaks that result following conventional 2D phase unwrapping.

\section{Results}

The unwrapped aliasing-free phase-contrast images (VENC $=20 \mathrm{~cm} / \mathrm{s}$ ) are shown in Fig. 1. The algorithm was insufficient to resolve phase wrapping produced form $10 \mathrm{~cm} / \mathrm{s}$ acquired datasets, specifically during the early filling stage (detail not presented). The profiles of blood-flow in the LV and RV $($ VENC $=20 \mathrm{~cm} / \mathrm{s}$ ) are close to that acquired with $75 \mathrm{~cm} / \mathrm{s}$ (Fig. 2a). The results of mid-ventricula regional wall motion (Fig $2 b$ ) are similar to those reported by other groups. Additionally, we include the results of RV wall motion.

\section{Conclusions}

Our preliminary results suggest that phase unwrapping using an orthogonal recursive technique can resolve phase wrap artifact from datasets acquired at VENC settings as low as $20 \mathrm{~cm} / \mathrm{s}$. This approach allows for simultaneous quantification of tissue and blood flow velocities within a single image acquisition and may be of value for the rapid assessment of diastolic dysfunction and left atrial pressures.

\section{Funding}

Partial Ontario Research Fund and NSERC.

\footnotetext{
Author details

${ }^{1}$ Imaging Research Laboratories, Robarts Research Institute, Schulich School of Medicine \& Dentistry, The University of Western Ontario, London, ON, Canada. ${ }^{2}$ Division of Cardiology, Department of Medicine, Schulich School of Medicine \& Dentistry, The University of Western Ontario, London, ON,
}

(C) 2012 Liu et al; licensee BioMed Central Ltd. This is an open access article distributed under the terms of the Creative Commons Attribution License (http://creativecommons.org/licenses/by/2.0), which permits unrestricted use, distribution, and reproduction in any medium, provided the original work is properly cited. 


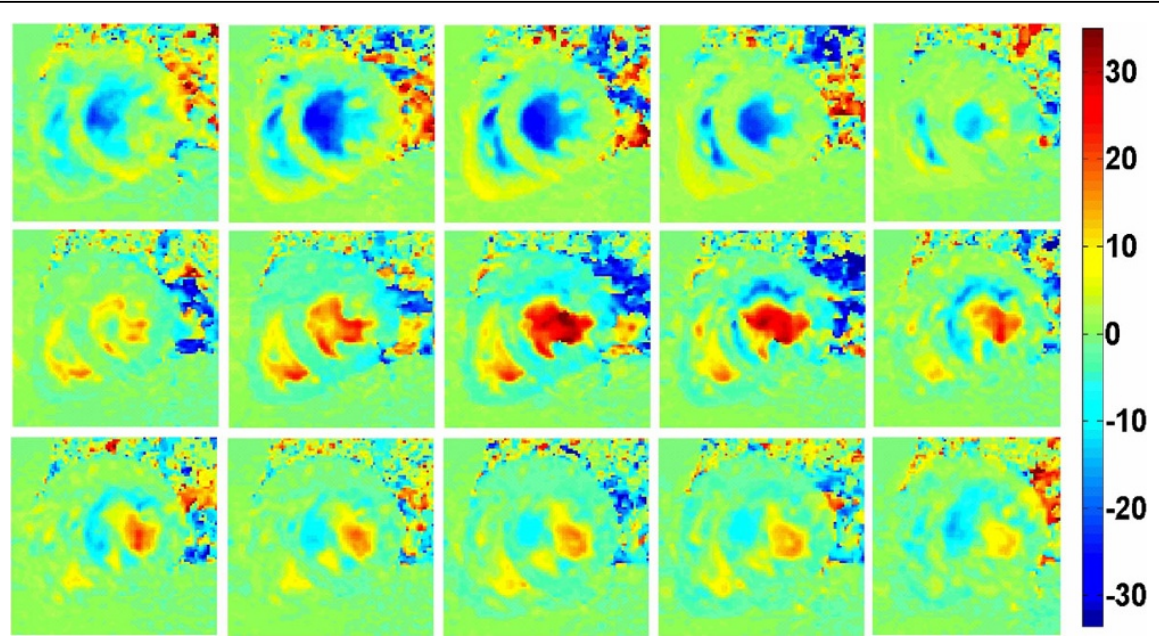

Figure 1 The odd-numbered time frames of the 30 unwrapped mid-ventricular phase images (VENC $=20 \mathrm{~cm} / \mathrm{s})$. The phase images have been corrected for background phase and are colour-coded in $\mathrm{cm} / \mathrm{s}$ according to the scale on the right.

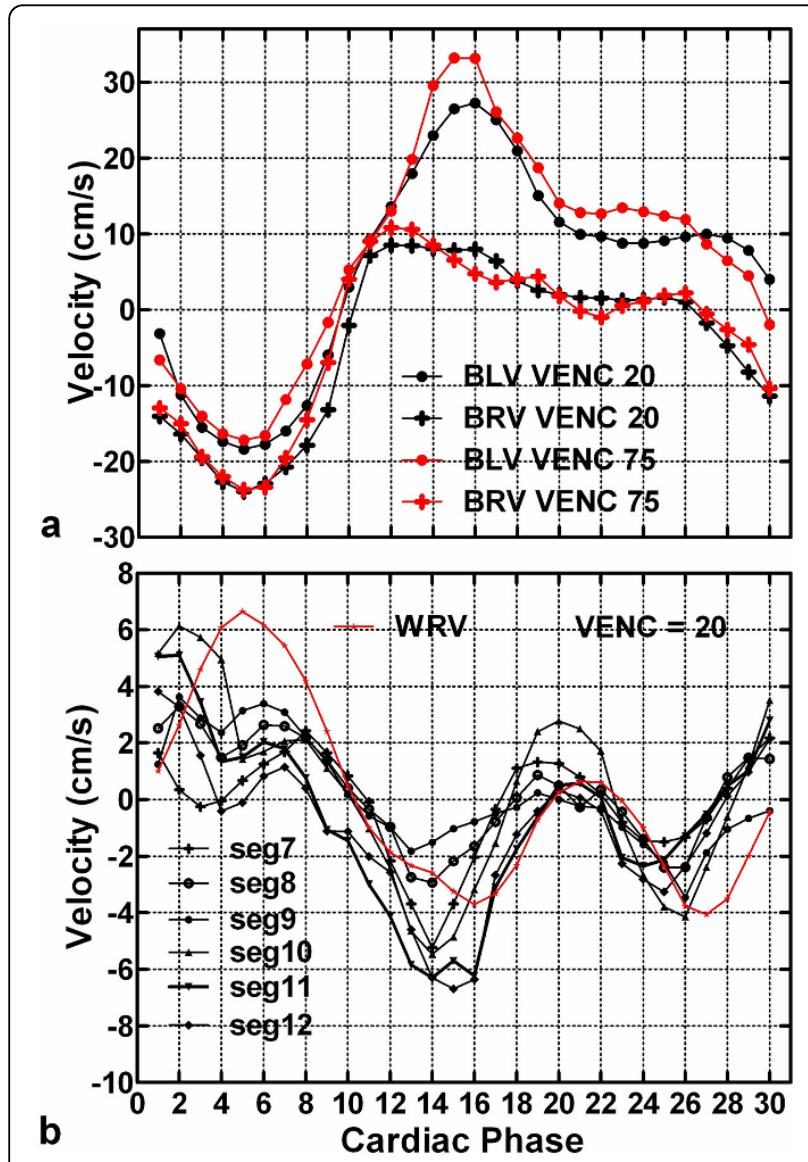

Figure 2 (a) The blood flow velocity in the LV (BLV) and RV (BRV) (b) Plots of regional wall motion of the middle ventricular plane. WRV denotes the lateral wall of the RV.
Canada. ${ }^{3}$ Department of Medical Biophysics, Schulich School of Medicine \& Dentistry, The University of Western Ontario, London, ON, Canada.

Published: 1 February 2012

doi:10.1186/1532-429X-14-S1-P241

Cite this article as: Liu et al.: Simultaneous measurement of blood-flow velocity and regional wall motion with phase unwrapping. Journal of Cardiovascular Magnetic Resonance 2012 14(Suppl 1):P241.
Submit your next manuscript to BioMed Central and take full advantage of:

- Convenient online submission

- Thorough peer review

- No space constraints or color figure charges

- Immediate publication on acceptance

- Inclusion in PubMed, CAS, Scopus and Google Scholar

- Research which is freely available for redistribution 